\title{
Feedback Loop Reasoning and Knowledge Sources for Elementary Students in Three Countries
}

\author{
Hayat Hokayem ${ }^{1 *}$, Hui Jin ${ }^{2}$, Etsuji Yamaguchi ${ }^{3}$ \\ ${ }^{1}$ Texas Christian University, USA \\ 2 Educational Testing Service, USA \\ ${ }^{3}$ Kobe University, JAPAN
}

Received 13 May 2019 - Revised 2 September 2019 - Accepted 25 September 2019

\begin{abstract}
Feedback loop reasoning is an important stepping-stone toward systems thinking. To date, studies on feedback loop reasoning in ecology have focused on college students, while only a limited effort has been made to investigate a more general systems thinking of students at the lower elementary level. The goal of this study is to investigate how elementary students reason about feedback loop relationships among interdependent organisms (predator-prey), and address the knowledge sources of students as part of context of reasoning about this topic. This study was conducted in three countries, with 128 first through fourth grader participants from Japan, Lebanon, and the United States. These students participated in semi-structured clinical interviews focusing on the predator-and-prey relationships. We found that the majority of students used one-way causal reasoning, and only a few students reasoned using twoway causality with multiple feedback loops in the predator-prey relationship.
\end{abstract}

Keywords: learning progression, feedback loop reasoning, predator-prey relationships

\section{INTRODUCTION}

The National Research Council (NRC) developed a framework (NRC, 2012) and the Next Generation Science Standards (NGSS) which emphasize promoting three-dimensional learning in science classrooms. The three dimensions are science and engineering practices, crosscutting concepts, and disciplinary core ideas (NRC, 2012). Science and engineering practices are specific components of scientific inquiry; crosscutting concepts are themes connecting science disciplines (e.g., patterns, scale, structure and function); disciplinary core ideas are foundational ideas in each science discipline (NRC, 2012). This study focuses on the following components of the three dimensions: Regarding scientific practices, we focus on the practice of constructing scientific explanations which is an important competency for elementary students (McNeill \& Krajcik, 2012); regarding disciplinary core ideas, we focus on one core idea in the life sciences: interdependent relationships in ecosystems (LS2.A), and regarding crosscutting concepts, we focus on feedback loops, a concept addressed in the crosscutting concept of systems and system models. Feedback loop refers to the mechanism in which the output of a system is circled back as the input of the system to either amplify a change (positive feedback loop) or suppress a change (negative feedback loop). Using feedback loops to analyze interdependent relationships in ecosystems is an important topic for elementary students because it introduces a specialized way of thinking that is counter-intuitive and foundational for future science learning (Grotzer \& Bell, 2003). Scientific explanations differ from everyday explanation in that they contain causal mechanisms which tell about how and why things happen (Braaten \& Windschitl, 2011; Hokayem, Ma, \& Jin, 2015). Feedback loops describe the causal mechanisms that explain events about interdependent relationships in ecosystems; such causal mechanisms include the predator-prey cycle, trophic cascades, exponential growth, carrying capacity, and so forth. Elementary students are expected to learn the concept of feedback loops - the outcomes of a system are routed back as input to amplify or inhibit the system, because it builds a foundation for the students to learn about more sophisticated mechanisms such as the cyclical oscillations among organism populations later in middle schools (Jin et al., 2019).

(C) 2020 by the authors; licensee Modestum Ltd., UK. This article is an open access article distributed under the terms and conditions of the Creative Commons Attribution License (http://creativecommons.org/licenses/by/4.0/).

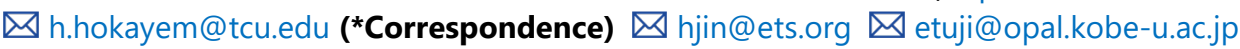




\section{Contribution of this paper to the literature}

- This paper contributes to the learning progression literature by refining a learning progression on feedback loop reasoning.

- $\quad$ This paper recognizes the importance of knowledge sources in elementary students' reasoning of science.

To date, limited research has investigated elementary children's reasoning of feedback loops with a few exceptions. For instance, Roberts (1978) conducted a pilot study to assess if the feedback system concepts could be taught to fifth and sixth graders. The students learned how to read feedback loop diagrams and then were given stories with different feedback loop scenarios (e.g., economics of oil prices and the predator-prey relationship) to analyze by drawing diagrams and answering questions. The study found that students were able to use analysisand synthesis-level thinking, using the same exercises that were previously administered to students at the Massachusetts Institute of Technology. In relation to ecosystems, Hovardas (2016) found that high school students think in a linear one direction about predator-prey relationships.

Learning progressions (LPs), "descriptions of successively more sophisticated ways of thinking that can follow one another as children learn about and investigate a topic over a broad span of time (NRC, 2007, p. 219)", are a powerful tool to investigate student thinking. A LP can be thought of as "vertical development over an extended period of time" (Heritage, 2008, p. 4). LPs (LPs) are characterized by a lower anchor which represents students' initial conceptions and an upper anchor which represents the appropriate scientific information as dictated by the national and international standards with middle levels in between the anchors (Salinas, 2009). They can be used as tools to aid teachers with assessment and instruction to informing curriculum design (Furtak, Thompson, Braaten, \& Windschitl, 2012; Heritage, 2008; Jin, Johnson, Shin, \& Anderson, 2017). LPs vary on two aspects. First, progressions can range from a narrow age span of groups such as middle school students only (Alonzo \& Steedle, 2009) to a much broader age span such as primary and secondary students (Mohan, Chen, \& Anderson, 2009). Second, the grain-size and scope of what is studied varies in how detailed the LP is from narrow to broad depth (Alonzo \& Gotwals, 2012). The idea of using LP in this study is to track students' ideas before they formally learn about the topics and to find the different levels of reasoning. Students have their own interpretation or explanations even before instruction (Carey, 1985); therefore, the rationale of this study is to identify the different levels of reasoning. This differs from the work on just misconceptions because whereas the misconception literature identifies the "wrong" scientific ideas, the learning progression research aims to pinpoint the explanation and similarities and differences that those explanations share with the appropriate scientific explanations (For a detailed historical review on learning progressions please see Jin, Mikeska, Hokayem \& Mavronikolas, 2019).

There have been many research studies about LP in the US (examples include; Hokayem \& Gotwals, 2016; Hokayem \& Jin, 2018; Jin \& Anderson, 2012; Mohan, Chen \& Anderson, 2009). Researchers from Europe and Asia have also used the LP approaches to study teaching and learning. For instance, in the United Kingdom, Johnson and Tymms (2011) conducted a longitudinal study (ages 11-14) across 30 schools to assess students' understanding of a substance such as its properties and chemical changes. Two other LPs were developed in Germany. Neumann, Viering, Boon, and Fischer (2013) developed an LP on energy across three grades $(6,8$, and 10) and found that students did not necessarily develop more complex knowledge from energy forms and sources to energy transformation and conservation. Hadenfeldt et al. (2016) evaluated students (grades 6-12) across five schools on four big ideas on the topic of matter; overall, students developed their learning in three of the four ideas in parallel (structure and composition, physical properties, and chemical change) with less conceptual understanding of chemical reactions. To promote the use of LPs, Wickman (2014) emphasizes the international approach in designing a LP that takes into consideration multiple contexts. Moreover, LP studies from Asian countries include force and motion in Singapore and Hong Kong (Fulmer, 2014, Vyas, 2015, respectively), astronomical systems in Korea (Maeng, Lee, Park, Lee, \& Oh, 2014), and feedback loop reasoning in Japan (Hokayem et al., 2015). Building upon this research base, an important research venue is using the LPs to compare the learning progressions different regions with students holding different backgrounds. Moreover, students from different social, cultural, and educational backgrounds may use very different knowledge sources to learn science.

To address the above research needs, we investigated how elementary students from different background countries drew upon their diverse knowledge sources to build feedback loop reasoning in elementary schools. In a prior study, we developed an LP that describes how elementary children use feedback loop reasoning to understand interdependent relationships in ecosystems (Hokayem et al., 2015). Using this developed LP, we compared the feedback reasoning of students from three different countries, including the United States, Lebanon, and Japan. Our research questions are:

1- How do students from different background countries reason about interdependent relationships in ecosystems?

2- What are the various knowledge sources that students cite as influencing their responses? 
Table 1. Number of Participants in Each Grade and Country

\begin{tabular}{cccc}
\hline Grade Level & Japan & Lebanon & United States \\
\hline $1^{\text {st }}$ grade & 15 & 6 & 12 \\
\hline $2^{\text {nd }}$ grade & 14 & 9 & 12 \\
\hline $3^{\text {rd }}$ grade & 12 & 10 & 10 \\
\hline $4^{\text {th }}$ grade & 9 & 9 & 10 \\
\hline Total & 50 & 34 & 44 \\
\hline
\end{tabular}

\section{Conceptual Framework}

In the prior study (Hokayem et al., 2015), we developed an LP for feedback reasoning at the elementary school level. We asked elementary students to reason about predator-prey relationships over time in a sustainable or unsustainable ecosystem. An ecosystem is sustainable if the normal set of conditions are maintained by positive and negative feedback loops, whereas an unsustainable ecosystem occurs when the conditions are shifted to a new state of conditions, such as through positive feedback loops (Chapin, Torn, \& Tateno, 1996). The results from Hokayem et al. (2015) showed that few students recognized the cyclic relationships in food webs and did not reason consistently across the sustainable and unsustainable ecosystem. In that study, the participating students came from one particular context: a Midwestern elementary school in the United States. Students from different social and cultural contexts may reason about the same ecosystem phenomena in very different ways. As such, the LP may not hold true for students from other backgrounds of the United State, or for students from Lebanon and Japan. Therefore, it is important to explore whether this LP applies to students from different countries and use the results to revise the LP levels.

From a multicultural perspective, sources of knowledge may influence student knowledge of the natural environments. It is possible that students from some countries with similar backgrounds share similar sources of knowledge, but emphasize one source of knowledge over another when constructing explanations. Blum (1987) compared high school students from Australia, England, and Israel on their sources of knowledge for environmental issues and found that they all stated the media (radio, television, and the press) as the most frequent source of knowledge. However, the differences in the rankings of the sources of knowledge among the three countries appeared to influence students' knowledge on environmental issues. For instance, students from Israel scored higher on questions related to ecology, and this high score was related to their second most frequent source of knowledge, which was biology and ecology in school. However, the other two countries cited general education as their second most frequent source of knowledge, and this did not correlate with a high score in ecology (Blum, 1987). Understanding both students' ideas of predator-prey relationships and where their ideas originate from might provide a more comprehensive view of sources that may influence students' conceptions. Furthermore, this information could be used to guide teachers' instruction, such as relating the sources of knowledge to their understanding of ecosystem ideas, and support the curriculum.

\section{METHODS}

\section{Participants}

The participants in this study were from Japan, Lebanon, and the United States $(n=128)$; see Table 1 . The ages of the students ranged from 6 until 10 years old, and have not learned about ecosystems formally in the school. Students from Japan consisted of 50 students from 1 st $44^{\text {th }}$ grade with a total of 26 females and 24 males. The Japanese students were from a provincial town, and the majority of students are from the middle class. Students from Lebanon consisted of 34 students from $1^{\text {st }} 4^{\text {th }}$ grade with a total of 15 females and 19 males. The students were from low middle class status in an urban school. Students from the United States consisted of 44 students from $1^{\text {st }} 4^{\text {th }}$ grade with a total of 22 females and 20 males. The U.S. students were from a suburban school in a Midwestern state where about one third of students at the school are economically disadvantaged. Note the data from the US students were collected as part of a bigger study to investigate LPs of systemic reasoning about ecosystems by the first author (Hokayem \& Gotwals, 2016). It is worth noting to mention that students of the Lebanese context lived in an urban area in the capital Beirut. Therefore, they did not have access to as many green spaces as the US and Japanese students had. Even though many of the Lebanese students would visit their countryside where their grandparents lived, we believe that they did not often have the same experience with nature and animals as the other two samples had. The students from these countries were chosen as convenience samples and details of this sample is include in Table 1. 


\title{
Interviews
}

We conducted semi-structured interviews to investigate to what extent students used feedback reasoning to explain phenomena about relationships in ecosystems, and what and how students drew upon knowledge sources to construct those explanations. Semi-structured interviews allowed students to "go beyond simple recognition of a concept to construct a detailed personal explanation" (Southerland, Smith, \& Cummins, 2000, p. 73). We first developed an English version of the interview protocol, and then translated the English version into a Japanese version. The Lebanese sample is a special sample because even though the native language of the country is Arabic, science and mathematics are taught in English or French. For the specific school where we conducted the interviews, science was taught in English. Therefore the interview was in English, but the interviewer would use code-switching at times to Arabic to make sure a certain idea is understood. We presented students with a picture of wolves and rabbits and asked them several questions. The first question was to have them reason what would happen to the number of the foxes and possums/rabbits after one week, assuming we started with 200 in each population in a stable environment (where water and food were abundant). In the second question, we asked what the abundance of each population would be after one month, six months, and one year and why. The students provided answers, and the researchers asked follow-up questions to probe their reasoning.

Following the interview on students' reasoning of ecosystems, we were interested in students' sources of knowledge about ecosystems including predator and prey relationships. We also interviewed students about where they learned about this topic from. We then categorized student responses into the following sources of knowledge: archaeology museums ${ }^{1}$, books, television shows and similar media, parents, other individuals like parents, personal experience, science museums and centers, their village ${ }^{2}$, and other (travel or website). If the category was applicable, we marked the category once. If the student did not know the source of their knowledge, we categorized the response as "does not know." Because we ended up having 28 students (from Japan) who did not know their sources of knowledge, we decided to take a more qualitative approach comparing the presence and absence of sources of knowledge among the three countries.

\section{Data Analysis}

Earlier, Hokayem et al. (2015) described a LP for feedback loop reasoning using only participants from the United States. The LP had seven levels:

- Level 1: both predator-prey are independent

- Level 2: one-way simple causal reasoning recognizing only food

- Level 3: one-way complex causal relation recognizing food and reproduction

- Level 4: one-way complex causal relation recognizing both populations: 4a) increase for both populations 4b) decrease for both populations

- Level 5: two-way simple causality

- Level 6: two-way simple causality with emerging attention to predator's cycle

- Level 7: two-way cyclical relationship that demonstrates a dynamic change in both populations

Even though those seven levels presented a fine-grained LP, we observed that some student responses could have been categorized in more than one similar level of reasoning. Here is one excerpt illustrating how students provided such responses when asked about predator and prey abundance over time (S: Student; I: Investigator):

\author{
Example 1 from a $4^{\text {th }}$ grade female: \\ [Note: This student uses the word rodent and rabbit interchangeably]. \\ S: The rodents won't have any food but the fox would eat them. There'll be probably about 100 rabbits \\ and 300 foxes because the rodent would be eaten by foxes. After 6 months, the foxes will produce more \\ babies and the rodent [population] will get smaller and smaller. After one year, the foxes will hit 1,000 \\ foxes and rabbits [will be] extinct. The more the population for fox grows, the less for rabbits.
}

\footnotetext{
${ }^{1}$ Note that in Beirut, Lebanon, when people refer to the museum, they are referring to this one archeological museum, and this is the reason it is included in here.

${ }^{2}$ Note that all students in the Lebanese sample lived in Beirut where the study was conducted; however, almost all of them have origins from the mountain villages. They visit their grandparents and relatives in the small villages often.
} 
I: Wouldn't rabbits reproduce as well?

S: Oh yea, they probably will keep having a 100 because they have plants to eat.

This student first answered that the prey will eventually become extinct from the foxes consuming them (level 2 , one-way causal reasoning), but she then stated that rabbits will reproduce because "they have plants to eat," which suggests both predator and prey populations will increase (level 4, one-way complex reasoning).

To resolve the issue of student responses that spanned similar levels of conceptual reasoning, we decided to revise the levels. Shea and Duncan (2013) noted that LPs need to be systematically revised and refined to depict an accurate description of students' reasoning, and there are several examples of LPs that have been refined in practice. Furtak et al. (2012) revised a LP on natural selection by merging two representations on natural selection into "a combination core LP" that still conserved the main ideas (p. 422). Jin \& Anderson (2012) revised their LP and added more levels on U.S. and Chinese students' reasoning of carbon-transforming processes because each culture used different words to describe the same carbon processes. Todd and Kenyon (2015) also revised a LP about genetics by splitting and merging some levels.

In this study, we revised the LP by merging levels to resolve the issue of having responses belonging to several levels simultaneously. We noticed that levels $2,3,4 \mathrm{a}$, and $4 \mathrm{~b}$ of the original LP were all describing a pattern of an increase or a decrease in either or both of the populations. We therefore collapsed those levels under one category. Similarly, we noticed that levels 6 and 7 both described one full feedback loop or a repeated feedback loop, and we decided that those can be collapsed under one category 4 (see Table 2 which demonstrates how we collapsed those levels). Two researchers coded the interview transcripts independently. In this blind coding process, the researchers achieved an $85 \%$ agreement. Disagreements were resolved through discussion.

Table 2. Comparison of Original and Revised levels of the LP

\begin{tabular}{l|l}
\hline $\begin{array}{l}\text { Original Levels } \\
\text { Level 1: Independent Populations }\end{array}$ \\
$\begin{array}{l}\text { Revised Level } \\
\text { Predator }\end{array}$ \\
$\begin{array}{ll}\text {--- Prey } \\
\end{array}$
\end{tabular}

${ }^{3}$ Note that all original levels have been derived from Hokayem et al. (2015).

${ }^{4}$ Note that the data from Japan and Lebanon were collected specifically for this study to refine the learning progression. The data from the US were re-analyzed for the purposes of this study. 
Table 2 (continued). Comparison of Original and Revised levels of the LP

\section{Original Levels ${ }^{5}$}

Level 2: One-way causal reasoning

- Predator

---- Prey

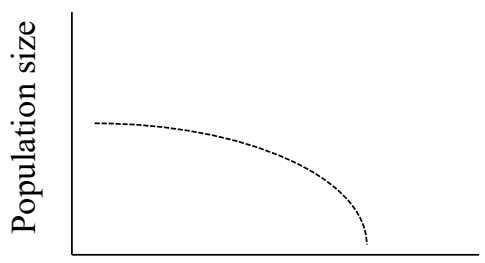

Time
Revised Level

Level 2: Action with consequence, without feedback

The student recognizes one-way causality for one or both populations but does not recognize any feedback loops.

Level 3: One-way complex reasoning for the predator population

- Predator

---- Prey

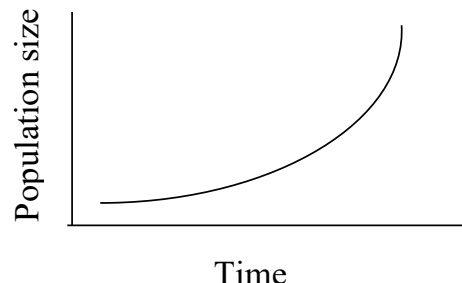

Level 4a and 4b: One-way complex reasoning for both

populations. $4 a$-increase for both populations. $4 b$-decrease for both populations.

- Predator

---- Prey
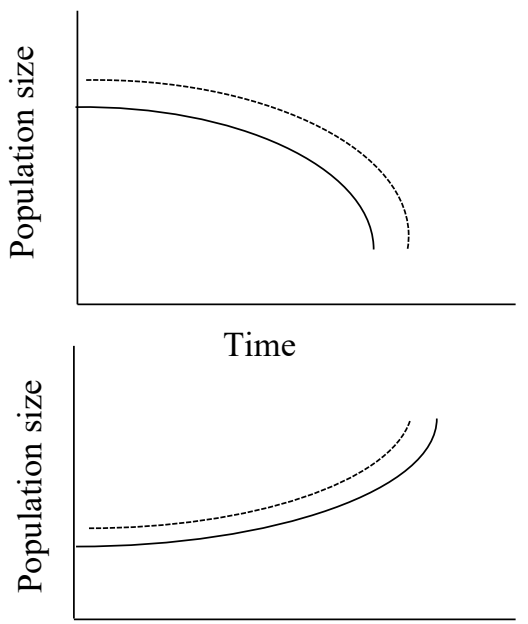

Time

${ }^{5}$ Note that all original levels have been derived from Hokayem et al. (2015). 
Table 2 (continued). Comparison of Original and Revised levels of the LP

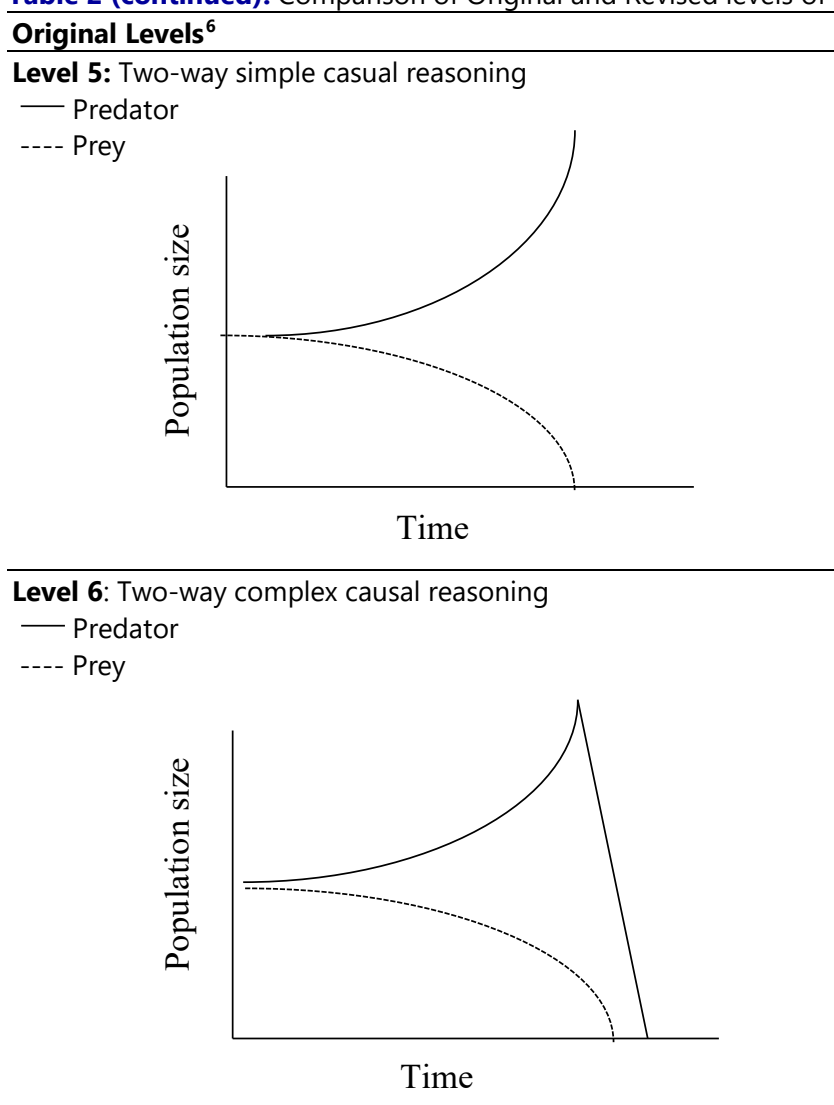

Revised Level

Level 3: Feedback loop without a cyclic pattern

The student recognizes two-way causality with one feedback loop, but does not recognize a cyclic pattern.

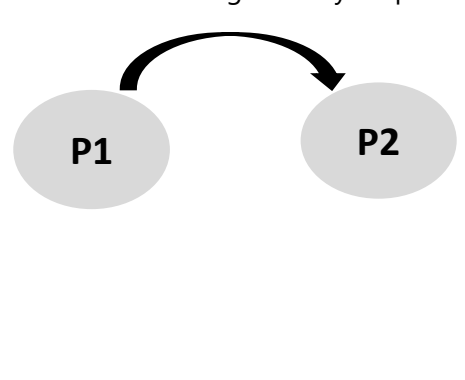

\section{Level 4: Feedback loop with recognition of a cyclic pattern}

The student recognizes: 1) two-way causality and 2) a repeated feedback loop.
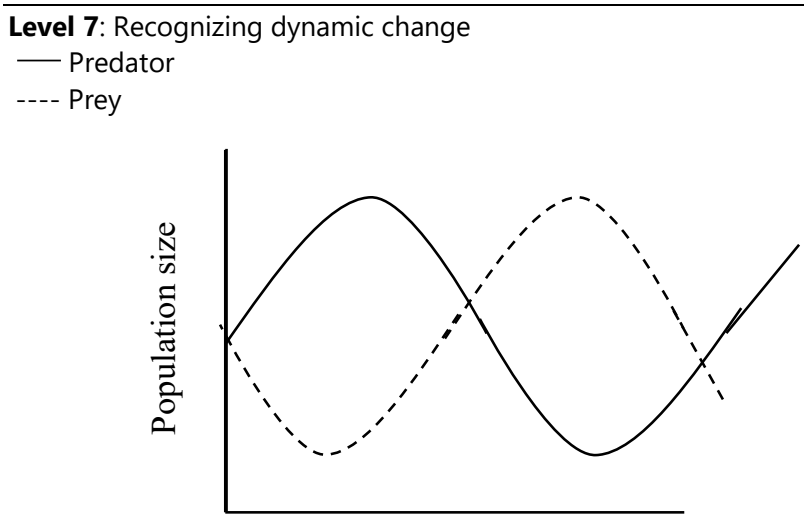

Time

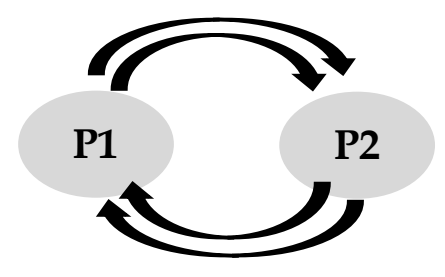

\section{RESULTS}

\section{Student Achievement}

We report the distribution of student responses along the revised LP (Figure 1). Collectively, 42 out of 128 students $(33.3 \%)$ reasoned at level one where students did not recognize interdependency between the predator and prey. The majority of students (64 out of 128 students or $50.8 \%$ ) reasoned at level two where there was a oneway causal relationship between the predator and prey. Very few students reasoned at level three (8.7\%) and level four $(7.1 \%)$, in which both levels consisted of at least one closed feedback loop but the latter considered multiple feedback loops. Similar trends of performance were observed in the data from the participating students in the

${ }^{6}$ Note that all original levels have been derived from Hokayem et al. (2015). 


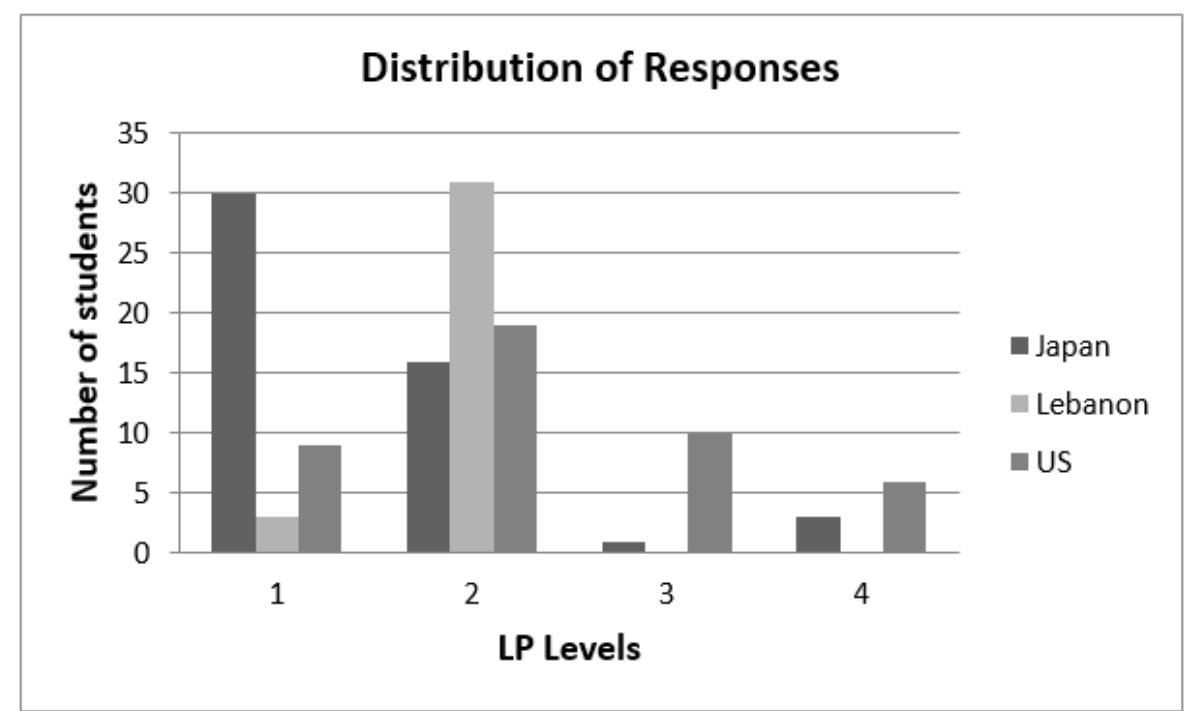

Figure 1. The number of responses corresponding to each level of the LP by student subgroup

three countries. Specifically, the highest level frequency was Level 1 for the Japanese students and Level 2 for both Lebanese and US students.

Most participating Japanese students reasoned at level 1 (60\%), almost one-third reasoned at level 2 (32\%), and there were few responses at level $3(2 \%)$ and level $4(6 \%)$. A small number of participating Lebanese students reasoned at level $1(9.38 \%)$, with the majority of students reasoning at level 2 (90.6\%); no students reasoned at levels 3 and 4. Two responses were not applicable to any of the levels because the students stated that they did not know the answer. Regarding the participating U.S. students, about one-fifth reasoned at level 1 (20.5\%), more than twofifths reasoned at level $2(43.2 \%), 22.7 \%$ reasoned at level 3, and 13.6\% reasoned at level 4 . To compare student responses on feedback loop reasoning among the countries, we provide a few examples to highlight their reasoning at each level (Table 3).

Table 3. Examples of Student Responses and Interpretations of Level of Understanding at Each Level of the LP for Question 1 : Assume that in the environment above, all animals died and what was left was 200 foxes and 200 possums/rabbits. How many possums/rabbits will we have after one week? After one month? After six months? After one year? Why?

\begin{tabular}{|c|c|c|c|}
\hline & Japan & Lebanon & United States \\
\hline Level 1 & G1M & G3F & G3F \\
\hline $\begin{array}{l}\text { No relationship between the } \\
\text { predators or prey populations }\end{array}$ & $\begin{array}{l}\text { S: Umm... if it's one week, it will } \\
\text { probably be hot, so one } \\
\text { hundred -no, about fifty, will } \\
\text { pass out or something of } \\
\text { heatstroke. } \\
\text { The student recognizes that the } \\
\text { prey can die of a heatstroke, but } \\
\text { does not recognize predators } \\
\text { consuming prey }\end{array}$ & $\begin{array}{l}\text { S: Rabbits will eventually die because } \\
\text { there is nothing in nature anymore. } \\
\text { The student recognizes that the } \\
\text { limitation of resources can lead to } \\
\text { death, but does not recognize } \\
\text { predators consuming rabbits. }\end{array}$ & $\begin{array}{l}\text { S: } 150 \text { possums because people will kill } \\
\text { them. } \\
\text { I: What if no one killed them will they } \\
\text { make more of themselves? } \\
\text { S: Yes, but it takes a while. } \\
\text { l: Will foxes eat the possums, what do } \\
\text { foxes eat? } \\
\text { S: Maybe birds and spiders and crickets. } \\
\text { The student recognizes that if humans did } \\
\text { not hunt possums, they can reproduce } \\
\text { more individuals. However, the student } \\
\text { does not recognize that foxes eat possums, } \\
\text { but rather eats birds, spiders, and crickets. }\end{array}$ \\
\hline Level 2 & G1F & G4M & $\mathrm{G} 2 \mathrm{~F}$ \\
\hline $\begin{array}{l}\text { One-way causal relationship } \\
\text { between the predator and prey } \\
\text { populations }\end{array}$ & $\begin{array}{l}\text { S: First, one will be gradually, } \\
\text { um, eaten, and gradually, um, } \\
\text { be looked at by the foxes as } \\
\text { delicious, and it is eventually } \\
\text { eaten and dies, and the } \\
\text { population declines. } \\
\text { The student recognizes a one- } \\
\text { way relationship where the fox } \\
\text { will consume the rabbits and } \\
\text { decrease the rabbit population, } \\
\text { but assumes all rabbits will } \\
\text { eventually die. }\end{array}$ & $\begin{array}{l}\text { S: Rabbits will die because they will } \\
\text { be hungry and die and then the } \\
\text { foxes will eat them. } \\
\text { The student recognizes a one-way } \\
\text { relationship where the foxes will eat } \\
\text { the rabbits. However, the student } \\
\text { assumes all rabbits will die. }\end{array}$ & $\begin{array}{l}\text { S: More foxes and less possums, the fox } \\
\text { will sneak on possums and eat them so } \\
\text { for foxes } \\
\text { I: Will possums make more of } \\
\text { themselves? } \\
\text { S: no } \\
\text { The student recognizes a one-way } \\
\text { relationship where the fox will eat the } \\
\text { possums, but assumes the possums will } \\
\text { not reproduce. }\end{array}$ \\
\hline
\end{tabular}


Table 3 (continued). Examples of Student Responses and Interpretations of Level of Understanding at Each Level of the LP for Question 1:

Assume that in the environment above, all animals died and what was left was 200 foxes and 200 possums/rabbits. How many possums/rabbits will we have after one week? After one month? After six months? After one year? Why?

\begin{tabular}{|c|c|c|c|}
\hline & Japan & Lebanon & United States \\
\hline Level 3 & G4M & Examples not found & G4M \\
\hline $\begin{array}{l}\text { Two-way causality between } \\
\text { predator and prey populations } \\
\text { with no cyclic pattern }\end{array}$ & $\begin{array}{l}\text { S: I think the foxes remain the same, } \\
\text { and } 150 \text { rabbits will be eaten by the } \\
\text { foxes, and most of them will be gone. } \\
\text { I: Okay, I see. Then, after one month, }\end{array}$ & & $\begin{array}{l}\text { S: All the rats will be gone, because foxes } \\
\text { will eat them, then foxes die out because } \\
\text { of food shortage. }\end{array}$ \\
\hline
\end{tabular}

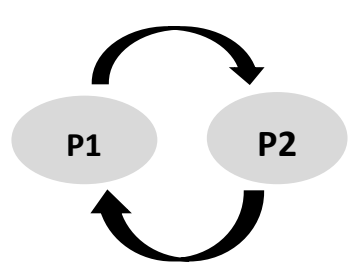

many each do you think will be

there?

S: I think the foxes will be like 210 or

50 , and the rabbits will be about 80 .

I: Why did the foxes increase?

S: Well, it's like living creatures eat and

give birth. Well, they ate rabbits and

gave birth, and that increased the numbers.

The student recognizes that the foxes eat rabbits (foxes will eat 150 rabbits leaving 50 rabbits) and then rabbits increase to 80 . The reproduction of rabbits provides more food for foxes to increase their numbers. Therefore, this describes one feedback loop. However, the student does not expand further to explain another feedback loop in which foxes will reduce the rabbit population which therefore decreases the fox population.

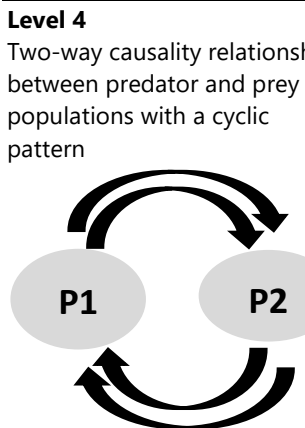
G3M

S: Um, I think that after one week, um, the rabbits are about 190, and well the foxes are about 210

I: Okay, well, why did the foxes increase?

A: They mated or something. And they sort of - they gave birth to offspring.

I: After six months, how many each do you think there are?

$\mathrm{S}$ : Well, the foxes increased a little - no decreased. The rabbits, well, increased a little. About 130

I: Okay, then. Why did the foxes decrease?

S: Well, um. There are foxes that were living from a few years ago, and animals and humans have life spans. So, the foxes, um, their lifespans, there were some foxes that reached their lifespans.

I: Then, why did the rabbits increase? S: Because the foxes decreased a little. Um, the amount that they could eat increased a little, um, and decreased. I: Um, okay, then after one year, how many each do you think there are?

$\mathrm{S}$ : Well, um, the foxes are the same as before. The rabbits increased a little.

The student recognizes that the rabbits provide food for the fox population to increase (one feedback loop) and then the fox population will decrease due to reaching their life spans which allows the rabbit population to increase (another feedback loop).

Examples not found $\quad$ G4F

The student recognizes that the foxes will eat rats and depleting the rat population could lead to food scarcity for foxes, thus decreasing the fox population. However, the student does not further expand further to indicate that the rat population could increase due to reproduction, and "feedback" again into providing more food for the foxes.

\author{
S: Probably maybe like in between 30 \\ and 50 of both of them, because I know \\ lots of them around the world could have \\ babies every day and they don't always \\ succeed in catching each other. \\ l:after one year \\ $\mathrm{S}$ : increase because more babies are born \\ in both.
}

This is a borderline answer between level 3 and 4. Although the student could provide a more thorough explanation, the student recognizes positive feedback loops because both populations will increase due to reproduction and acknowledges that not all foxes will successfully catch all rabbits/possums. 
Table 4. Knowledge Sources across Countries

\begin{tabular}{|c|c|c|c|}
\hline & Japan & Lebanon & United States \\
\hline Archaeology Museum & & $x$ & \\
\hline Books & $x$ & $x$ & $x$ \\
\hline Media/TV shows & $x$ & $x$ & $x$ \\
\hline Others like Parents & & $x$ & $x$ \\
\hline Other (travel or website) & $\mathrm{X}$ & & \\
\hline Parents & $\mathrm{X}$ & & $\mathrm{X}$ \\
\hline Personal Experience & $\mathrm{X}$ & $\mathrm{X}$ & $\mathrm{X}$ \\
\hline Science Museum/Center & & & $\mathrm{X}$ \\
\hline Teachers/School & & $\mathrm{X}$ & $\mathrm{x}$ \\
\hline Village & & $\mathrm{X}$ & \\
\hline
\end{tabular}

\section{Knowledge Sources}

We examined what knowledge sources our participating students used to answer the interview questions. A qualitative comparison of the presence and absence of knowledge sources among the countries is found in Table 4 . (Note that $\mathrm{X}$ indicates the presence of the knowledge source, and no $\mathrm{X}$ indicates the absence of that source).

The results showed that the three categories of common knowledge sources across the three countries were media/television shows, books, and personal experiences. Students reported watching television shows such as National Geographic and Animal Planet, Wild Kratts, and watching Disney movies such as The Lion King. Books ranged on a variety of animal topics including dinosaurs, dolphins, horses, and sharks. Personal experiences included students noticing nature when they walked home from school, attending nature camps, and camping and/or taking nature walks with their family. In contrast, there were sources of knowledge that were unique to each country. The participating Japanese students gained information from the "other" category which included travel experiences and Internet research. The participating Lebanese students cited their village (community) and visits to an Archaeology Museum as important sources of knowledge. The participating U.S. students visited science museums/centers such as the Impression 5 Museum in Michigan.

\section{DISCUSSION}

\section{Misconceptions about Interdependent Relationships}

Collectively, the majority of students (regardless of the country) recognized one-way causality with only about $16 \%$ of students recognizing two-way causality with multiple feedback loops (levels 3 and 4). Students' conception of the predator-prey relationship as a one-way causal relationship is consistent with previous research findings. Nevanpää and Law (2006) stated that children's naïve reasoning led to an over-exaggeration of the predators' impact on the prey. They also suggested that children's understanding of predator-prey interactions is more of a simple food chain rather than a complex food web. Similarly, Green (1997) found that undergraduate students were less likely to recognize two-way causality in predator and prey populations unless they were given a cue to consider interdependency. Hokayem et al. (2015) conducted a preliminary assessment of 12 Japanese elementary students on systemic interdependency, asking students to consider the predator-prey relationship in a context of the predator disappearing. The mean level of reasoning (on a scale of 1-5) was 3.1, and none of the students reasoned at the highest level on the progression. These studies illustrate that most students used linear thinking instead of non-linear, feedback reasoning.

Previous studies on students' systemic reasoning in ecology confirmed that few students tended to reason at the highest levels (Leach, Driver, Wood-Robinson, 1996). This is often due to limited exposure of feedback loop reasoning or food webs throughout classroom instruction and curriculum materials. Gallegos, Jerezano and Flores (1994) studied students' misconceptions on food webs as mentioned earlier, and also interviewed teachers on how much time is spent on teaching food webs. They found that fourth grade teachers spent between one to three hours per year on this topic. In addition, biology textbooks may not fully support students' understanding of food webs, as high school students held the misconception that a change in one population does not impact the remaining food web; nine out of eleven textbooks did not specifically address this misconception (Barman \& Mayer, 1994). Similarly, a comparison of high school students from the United States, Australia, and Canada on their understanding of food webs showed that they did not recognize interdependency in food webs (Barman, Griffith \& Okebukola, 1995). Grotzer and Bell (2003) emphasized the importance of pinpointing student misconceptions and finding ways to address those misconceptions as the first step in understanding interdependent relationships in ecosystems. 


\section{Levels of Reasoning and Sources of Knowledge}

The revised LP allowed us to capture student reasoning about predator and prey relationships. A noticeable difference among the students from three countries is that most participating U.S. students reasoned at levels 2 and 3 , while most participating Japanese and Lebanese students reasoned at levels 1 and 2. Additionally, more students from the U.S. achieved Level 4 of the LP. Overall, the students from the U.S. demonstrated a higher achievement than the students from the Lebanese or Japanese backgrounds. Students' use of different knowledge sources may have contributed to the differences in their achievement because the participating students had not received any formal instruction on feedback loops and predator-prey relationships. The results showed that the students from all three countries drew upon a variety of knowledge sources to answer the questions about predator-prey relationships, indicating that knowledge sources could be an important factor affecting student learning. While students at Level 3 and Level 4 were able to recognize that the outcome could function as an input for the system, students at Level 1 and Level 2 primarily reasoned about one-way simple causality. It is possible that the knowledge from different sources helped the U.S. students to build relatively advanced reasoning. However, this study did not investigate whether a causal or correlational relationships existed between the achievement on the LP and the knowledge sources. It would be interesting for future research to examine how students' sources of knowledge from a cultural perspective influence student reasoning. An avenue of research could be to relate sources of knowledge to the understanding of environmental concepts, as it does appear that sources of knowledge may differ across cultures.

Our findings of sources of knowledge across countries are similar to Blum (1987), which found differences in sources of knowledge among students from three countries. In Blum's study, Israeli students drew upon more sources of knowledge from biology/ecology education in school and other subjects in schools, whereas the Australian and English students relied more upon general education in school. In another study that related cultural comparisons in the sources of knowledge, Palmer et al. (1998) assessed what factors (similar to sources of knowledge) influenced the environmental awareness of environmental educators from nine countries. The most important factor for respondents from Australia, Canada, South Africa, the United Kingdom, and Sri Lanka was direct experiences with nature; for respondents from Greece, Hong Kong, and Uganda, negative observations of nature such as pollution were reported as important factors; and people such as family were the most important factor to respondents from Slovenia. This means that it could be worthwhile from a multicultural perspective to understand the sources of students' ideas and to support their learning.

\section{Conclusions and Implications}

This study takes a fine-grained approach to the LP where the focus is on a narrow topic, and targets a specific school group (Alonzo \& Gotwals, 2012). Our LP focuses on feedback loop reasoning, a critical stepping stone for facilitating systems thinking at an early age. Specifically, the LP addresses feedback loops in predator and prey populations across elementary students from Japan, Lebanon, and the United States. This study has several implications for teacher instruction and revised LPs. First, few students were able to recognize a two-way causal relationship between the predator and prey with multiple feedback loops (level 4). This finding aligns with other findings that few students reach the highest level of reasoning on systems thinking (e.g., Hogan, 2000). Even at the lowest level (level 1) of the LP, more than half of the participants from Japan, one-third of students from the US, and almost $10 \%$ of students from Lebanon did not recognize the predator and prey populations as interacting populations. This is concerning, given that the Next Generation of Science Standards outlines in LS2 that students from third to fifth grade should be able to recognize interdependent relationships in ecosystems (NRC, 2012). Similarly the Japanese and Lebanese curricula call for teaching ecology at upper elementary levels. Second, this study suggests the need for teaching interdependent relationships in ecosystems in a way that capitalizes on students' knowledge sources. We believe that this can be achieved by using encounters in nature that students might be familiar with (e.g., ecosystems) or other sources of knowledge as a starting point to discuss feedback loops in the predator-prey relationship. For example using the media (e.g. Magic School Bus) episodes in the classroom is one way to capture students' interest, and build the appropriate scientific ideas.

The implications of this LP could theoretically provide a feasible scale for teachers to assess student reasoning on predator-prey relationships; however, the empirical validation is also important before one could recommend using it at a large scale. Shavelson and Kurpius (2012) emphasize that LPs should account for teachers' abilities to incorporate and use the LP. Empirical research suggests that understanding and using LPs to design and teach lessons is challenging for teachers (Furtak, \& Heredia, 2014; Hokayem et al., 2015). Similarly, Furtak et al. (2012) state that in order for a LP to support teachers' use, it has to have "instructional utility [which] involves presenting the content of the LP in ways that will be useful to teachers as they develop new teaching practices" (p. 406). Future research might include investigating how revised levels support teachers' use of a LP in the classroom. 


\section{REFERENCES}

Alonzo, A. C., \& Gotwals, A. W. (2012). LPs in science: Current challenges and future directions. Rotterdam: SensePublishers.

Alonzo, A. C., \& Steedle, J. T. (2009). Developing and assessing a force and motion LP. Science Education, 93(3), 389421. https://doi.org/10.1002/sce.20303

Barman, C. R., \& Mayer, D. A. (1994). An analysis of high school students' concepts \& textbook presentations of food chains \& food webs. The American Biology Teacher, 56(3), 160-163. https:/ / doi.org/10.2307/4449780

Barman, C. R., Griffiths, A. K., \& Okebukola, P. A. (1995). High school students' concepts regarding food chains and food webs: A multinational study. International Journal of Science Education, 17(6), 775-782. https:/ / doi.org/10.1080/0950069950170608

Blum, A. (1987). Students' knowledge and beliefs concerning environmental issues in four countries. The Journal of Environmental Education, 18(3), 7-13. https:/ / doi.org/10.1080/00958964.1987.9942734

Braaten, M., \& Windschitl, M. (2011). Working toward a stronger conceptualization of scientific explanation for science education. Science Education, 95, 639-669. https:/ / doi.org/10.1002/sce.20449

Carey, S. (1985). Conceptual change in childhood. Cambridge, MA: MIT Press.

Chapin III, F. S., Torn, M. S., \& Tateno, M. (1996). Principles of ecosystem sustainability. The American Naturalist, 148(6), 1016-1037. https:/ / doi.org/10.1086/285969

Fulmer, G. W. (2014). Validating proposed LPS on force and motion using the force concept inventory: Findings from Singapore secondary schools. https:/ / doi.org/10.1007/s10763-014-9553-x

Furtak, E. M., \& Heredia, S. C. (2014). Exploring the influence of LPs in two teacher communities. Journal of Research in Science Teaching, 51, 982-1020. https:// doi.org/10.1002/tea.21156

Furtak, E. M., Thompson, J., Braaten, M., \& Windschitl, M. (2012). LPs to support ambitious teaching practices. In LPs in science (pp. 405-433). Rotterdam: SensePublishers. https:/ / doi.org/10.1007/978-94-6091-824-7_17

Gallegos, L., Jerezano, M.E., \& Flores, F. (1994). Preconceptions and relations used by children in the constructions of food chains. Journal of Research in Science Teaching, 31(3), 259-272. https:/ / doi.org/10.1002/ tea.3660310306

Green, D. W. (1997). Explaining and envisaging an ecological phenomenon. British Journal of Psychology, 88(2), 199217. https:// doi.org/10.1111/j.2044-8295.1997.tb02630.x

Grotzer, T. A., \& Basca, B. B. (2003). How does grasping the underlying causal structures of ecosystems impact students' understanding? Journal of Biological Education, 38(1), 16-29. https:/ / doi.org/10.1080/00219266.2003.9655891

Hadenfeldt, J. C., Neumann, K., Bernholt, S., Liu, X., \& Parchmann, I. (2016). Students' progression in understanding the matter concept. Journal of Research in Science Teaching, 53(5), 683-708. https://doi.org/10.1002/tea.21312

Heritage, M. (2008). LPs: Supporting Instruction and Formative Assessment. Paper prepared for the formative assessment for teachers and students (FAST) state collaborative on assessment and student standards (SCASS) of the council of chief state school officers (CCSSO). Washington, DC. Retrieved from http://www.ccsso.org/Documents/2008/Learning_Progressions_Supporting_2008.pdf

Hogan, K. (2000). Assessing students' systems reasoning in ecology. Journal of Biological Education, 35(1), $22-28$. https:/ / doi.org/10.1080/00219266.2000.9655731

Hokayem, H., \& Gotwals, A. (2016). Early elementary students' understanding of complex ecosystems: A learning progression approach. Journal of Research in Science Teaching, 53, 1524-1545.

Hokayem, H., \& Jin, H. (2018). Elementary students' knowledge sources for understanding ecosystems. International Journal of Environmental and Science Education, 13, 631-645.

Hokayem, H., Ma, J., \& Jin, H. (2015). A learning progression for feedback loop reasoning at the lower elementary level. Journal of Biological Education, 49, 246-260.

Hovardas, T. (2016). A LP should address regression: Insights from developing non-linear reasoning in ecology. Journal of Research in Science Teaching, 53(10), 1447-1470. https:/ / doi.org/10.1002/tea.21330

Jin, H., \& Anderson, C. (2012). A learning progression for energy in socio-ecological systems. Journal of Research in Science Teaching, 49, 1149-1180.

Jin, H., Johnson, M. E., Shin, H.-J., \& Anderson, C. W. (2017). Promoting student progressions in science classrooms: A video study. Journal of Research in Science Teaching.

Jin, H., Mikeska, J., Hokayem, H., \& Mavronikolas, E. (2019). Toward coherence in curriculum, instruction, and assessment: A review of learning progression literature. Science Education, 103, 1206-1234. 
Jin, H., Shin, H.-J., Hokayem, H., Qureshi, F., \& Jenkins, T. (2019). Secondary students' understanding of ecosystems: A learning progression approach. International Journal of Science and Mathematics Education, 17(2), 217-235. https://doi.org/10.1007/s10763-017-9864-9

Johnson, P., \& Tymms, P. (2011). The emergence of a LP in middle school chemistry. Journal of Research in Science Teaching, 48(8), 849-877. https:/ / doi.org/10.1002/tea.20433

Leach, J. R., Driver, P. Wood-Robinson, C. (1996). Children's ideas about Ecology 2: Ideas found in children aged 5-16 about interdependency of organisms. International Journal of Science Education, 18(1), 129-141. https:/ / doi.org/10.1080/0950069960180201

Maeng, S., Lee, K., Park, Y. S., Lee, J. A., \& Oh, H. (2014). Development and validation of a LP for astronomical systems using ordered multiple-choice items. Journal of the Korean Association for Science Education, 34(8), 703718. https://doi.org/10.14697/jkase.2014.34.8.0703

McNeill, K. L., \& Krajcik, J. S. (2012). Supporting grade 5-8 students in constructing explanations in science: The claim, evidence, and reasoning framework for talk and writing. Boston: Pearson.

Mohan, L., Chen, J., \& Anderson, C. W. (2009). Developing a multi-year LP for carbon cycling in socio-ecological systems. Journal of research in science teaching, 46(6), 675-698. https:/ / doi.org/10.1002/ tea.20314

National Research Council. (2007). Taking science to school: Learning and Teaching science in grades K-8. Washington DC: The National Academies Press.

National Research Council. (2012). A Framework for K-12 Science Education: Practices, Crosscutting Concepts, and Core Ideas. Washington DC: The National Academies Press.

Neumann, K., Viering, T., Boone, W., \& Fischer, H. E. (2013). Towards a LP of energy. Journal of Research in Science Teaching, 50(2), 162-188. https:/ / doi.org/10.1002/tea.21061

Nevanpää, T. \& Law, N. (2006). Pupil's ecological reasoning with help of modeling tool. In Proceedings of the 2006 conference on Interaction design and children (pp. 41-44). ACM. https:/ / doi.org/10.1145/1139073.1139088

Palmer, J. A., Suggate, J., Bajd, B., Ho, R. K., Ofwono-Orecho, J. K. W., Peries, M., ... \& Staden, C. V. (1998). An overview of significant influences and formative experiences on the development of adults' environmental awareness in nine countries. Environmental education research, 4(4), 445-464. https:/ / doi.org/10.1080/1350462980040408

Roberts, N. (1978). Teaching dynamic feedback systems thinking: An elementary view. Management Science, 24(8), 836-843. https:// doi.org/10.1287/mnsc.24.8.836

Salinas, I. (2009). LPs in science education: Two approaches for development. In LPs in Science (LeaPS) Conference, Iowa City, IA.

Shavelson R.J., Kurpius A. (2012) Reflections on LPs. In: A. C. Alonzo, \& A. W. Gotwals (eds) LPs in Science (pp. 1326). Rotterdam: SensePublishers. https://doi.org/10.1007/978-94-6091-824-7_2

Shea, N. A., \& Duncan, R. G. (2013). From theory to data: The process of refining LPs. Journal of the Learning Sciences, 22(1), 7-32. https:/ / doi.org/10.1080/10508406.2012.691924

Southerland, S., Smith, M., \& Cummins, C. (2000). "What do you mean by that?" Using structured interviews to assess science understanding. In J. Mintzes, J. Wandersee, \& J. Novak (Eds.), Assessing science understanding (pp. 72-92). London: Academic Press.

Todd, A., \& Kenyon, L. (2016). Empirical refinements of a molecular genetics LP: The molecular constructs. Journal of Research in Science Teaching, 53(9), 1385-1418. https:/ / doi.org/10.1002/tea.21262

Vyas, P. A. (2015). Exploring LPs of form-4 physics students in Hong Kong using assessment for learning strategies. HKU Theses Online (HKUTO).

Wickman, P. O. (2014). Teaching LPs: An international perspective. In N. Lederman, \& S, Abell (Eds), Handbook of Research in Science Education (pp. 145-163). New York: Routledge.

\section{http://www.ejmste.com}

